\title{
Compound Sodium Lactate Solution
}

National Cancer Institute

\section{Source}

National Cancer Institute. Compound Sodium Lactate Solution. NCI Thesaurus. Code C120128.

A multiple electrolyte, isotonic, crystalloid solution for intravenous infusion containing sodium chloride, potassium chloride, calcium chloride dihydrate, and sodium lactate, which can restore the electrolyte balance, normalize $\mathrm{pH}$, and provide water for hydration. Upon intravenous administration, the compound sodium lactate solution will replace any lost body fluids and electrolytes thereby providing hydration as well as normalizing electrolyte concentrations. In addition, conversion of sodium lactate to bicarbonate increases plasma bicarbonate levels, which facilitates the removal of hydrogen ions from the blood stream, raises blood pH and normalizes the acid-base balance. 